\title{
ISOLASI ACTINOMYCETES DENGAN MENGGUNAKAN METODE SKRINING SEBAGAI PENGHASIL ENZIM KITINASE
}

\author{
Welly Anggraini \\ Program Studi Pendidikan Fisika, FTK IAIN Raden Intan Lampung; e-mail:
}

\begin{abstract}
Abstrak: Penelitian ini bertujuan untuk mengisolasi Actinomycetes yang memiliki kemampuan dalam mendegradasi kitin. Isolasi Actinomycetes dilakukan menggunakan media NaST21Cx selama 2-3 bulan dan purifikasi untuk mendapatkan isolat murni dilakukan menggunakan media ISP-2. Hasil dari penelitian ini yakni, empat isolat Actinomycetes, yang diberi kode ANL-4, ANL-9, ANL-12, dan ANL-d-2b-3 yang ditandai dengan ciri-ciri isolat yang keras dan melekat erat pada agar. Secara mikroskopis teramati adanya hifa dan spora yang terbentuk. Isolat ANL-4, ANL-9, ANL-12, dan ANLd-2b-3 memiliki kemampuan dalam mendegradasi kitin pada media uji mineral-salt agar plate dengan substrat kitin $1 \%(\mathrm{w} / \mathrm{v})$ yang diindikasikan dengan terbentukya zona bening yang diperjelas dengan penambahan Congo Red 1\% (w/v). Indeks kitinolitik yang dihasilkan berturut-turut : $5 \mathrm{~cm}, 2 \mathrm{~cm}, 1,9 \mathrm{~cm}$, dan $2,3 \mathrm{~cm}$.
\end{abstract}

Kata Kunci : actinomycetes, hutan bakau, kitin, kitinase 


\section{PENDAHULUAN}

Kitinase merupakan enzim yang mampu menghidrolisa polimer kitin menjadi oligosakarida atau $\mathrm{N}$-asetilglukosamin (Cohen-Kupiec and Chet, 1998). NAcetylglucosamin (N-Acetyl-DGlucosamine, atau GlcNAc, atau NAG) merupakan turunan monosakarida, glukosa, memiliki rumus molekul $\underline{\mathrm{C}}_{8} \underline{\mathrm{H}}_{15} \underline{\mathrm{NO}}_{6}$ dengan massa molar sebesar $221.21 \mathrm{~g} / \mathrm{mol}$, dikenal sebagai amida yang terdiri dari glukosamin dan asam asetat (Linden, J. et al., 2007). NAcetylglucosamin dapat dihasilkan dari kitin, dimana secara umum kitin banyak terdapat pada eksoskeleton atau kutikula serangga, crustacea, udang, jamur, cumicumi, dan artropoda lainnya (Tiffany A. Reese, et al., 2000). Bakteri yang menghasilkan kitinase adalah Actinomycetes, yaitu kumpulan mikroorganisme yang strukturnya merupakan bentuk antara bakteria dan jamur, mereka menghasilkan zat-zat anti mikroba dari asam amino yang dikeluarkan oleh bakteria fotosintetik dan bahan organik. Actinomycetes ini merupakan sumber kitinase, mudah didapatkan, mudah dikembangbiakkan, dan memiliki nilai ekonomi yang tinggi (Martín-Gil FJ, Leal JA, 1992 ).
Untuk memperoleh satu jenis bakteri (misalnya Actinomycetes) dari suatu bahan yang mengandung campuran mikroba, dapat dilakukan dengan cara isolasi mikroorganisme. Isolasi mikroorganisme dari alam atau sampel merupakan tahap awal dalam skrining metabolit mikroorganisme yaitu dengan menggunakan kitin sebagai sumber karbon satu-satunya di dalam media, dimana tujuan isolasi ini adalah untuk memperoleh mikroba Actinomycetes kitinolitik sebanyak-banyaknya melalui teknik diperkaya dan sistem pengenceran (Cermin Dunia Kedokteran No. 89, 1993). Penelitian ini bertujuan untuk melihat kemampuan actinomycetes melakukan skrining kitinase, mengetahui kondisi optimum pertumbuhan actinomycetes sehingga dapat menghasilkan enzim kitinase dalam jumlah yang tinggi, dan mengetahui spesies dan kekerabatan dari Actinomycetes penghasil enzim kitinase tersebut.

\section{METODE PENELITIAN}

\section{Media NaST21Cx}

Medium NaST21Cx terdiri dari larutan A ( $750 \mathrm{~mL}$ air laut steril, $1 \mathrm{~g} \mathrm{KH} \mathrm{KH}_{4}$ dan 10 g agar ) dan larutan $\mathrm{B}(250 \mathrm{~mL}$ air laut, $1 \mathrm{~g}$ $\mathrm{KNO}_{3}, 1 \mathrm{~g} \mathrm{MgSO}_{4}, 1 \mathrm{~g} \mathrm{CaCl}_{2} \cdot 2 \mathrm{H}_{2} \mathrm{O}, 0,2 \mathrm{~g}$ $\left.\mathrm{FeCl}_{3}, 0,1 \mathrm{~g} \mathrm{MnSO}_{4} \cdot 7 \mathrm{H}_{2} \mathrm{O}\right)$. larutan A dan 
larutan B diautoklaf secara terpisah selama 30 menit, kemudian dicampurkan dan ditambahkan dengan $10 \mathrm{~mL}$ trace element solution dan $25 \mu \mathrm{g}$ cycloheximide/mL (Margavey, Nathan A., et al., 2004).

\section{Media ISP - 2}

Medium ISP-2 terdiri dari $4 \mathrm{~g}$ yeast ekstrak, 10 g malt ekstrak, 4 g dekstrosa, dan $20 \mathrm{~g}$ agar dilarutkan dalam $1 \mathrm{~L}$ air laut steril kemudian diautoklaf. Setelah media sedikit dingin, ditambahkan cycloheximide $(25 \mu \mathrm{g} / \mathrm{mL})$ dan nalidixic acid $(25 \mu \mathrm{g} / \mathrm{mL})$ (Margavey et al., 2004).

\section{Media Trace Element Solution}

$\mathrm{CaCl}_{2} \cdot 2 \mathrm{H}_{2} \mathrm{O} 10 \mathrm{mM}, \mathrm{FeCl}_{3} \cdot 6 \mathrm{H}_{2} \mathrm{O} 1 \mathrm{mM}$, $\mathrm{MnSO}_{4} \cdot 7 \mathrm{H}_{2} \mathrm{O} 2,5 \mathrm{mM}, \mathrm{CuSO}_{4} \cdot 2 \mathrm{H}_{2} \mathrm{O} \quad 0,2$ $\mathrm{mM}, \mathrm{H}_{3} \mathrm{BO}_{3} 1 \mathrm{mM}, \mathrm{CoCl}_{2} \cdot 6 \mathrm{H}_{2} \mathrm{O} 0,1 \mathrm{mM}$, $\mathrm{ZnCl}_{2} \quad 0,5 \mathrm{mM}$, dan $\mathrm{NaMoO}_{4} \cdot 2 \mathrm{H}_{2} \mathrm{O} \quad 0,1$ $\mathrm{mM}$ dilarutkan dalam $0,1 \mathrm{~N} \mathrm{HCl}$.

\section{Isolasi Actinomycetes}

Isolasi Actinomycetes dilakukan dengan cara meletakkan kertas saring steril diatas media NaST21Cx yang memadat didalam cawan Petri. Kemudian sampel Lumpur disebar dan diratakan diatas cawan Petri tersebut dan diinkubasi pada suhu $30^{\circ} \mathrm{C}$ selama 8 hari. Koloni yang tumbuh, dipindahkan kedalam media ISP-2 hingga diperoleh kultur murni (Margavey, et al., 2004).

\section{Pengamatan Makroskopik}

Isolasi Actinomycetes secara makroskopik diamati pada akhir masa inkubasi dengan menumbuhkan isolat Actinomycetes pada media NaST21Cx (10 hari). Isolat Actinomycetes yang tumbuh diamati bentuk koloni, tepi koloni, warna, elevasi, dan pigmentasinya (Jutono, 1980).

\section{Pengamatan Mikroskopik}

Isolasi Actinomycetes secara mikroskopik diamati bentuk hifa dan spora yang terbentuk. Pengamatan dilakukan pada akhir masa inkubasi dengan menumbuhkan isolat Actinomycetes pada media NaST21Cx dengan menggunakan Illuminating System Zeiss Axio.

\section{Pereaksi Mineral Salt Medium dan Mineral Salt Agar plate}

Mineral salt medium $0,4 \%\left(\mathrm{NH}_{4}\right)_{2} \mathrm{SO}_{4}, 0,1$ $\% \mathrm{~K}_{2} \mathrm{HPO}_{4}, 0,01 \% \mathrm{MgSO}_{4} 7 \mathrm{H}_{2} \mathrm{O}, 0,01 \%$ $\mathrm{CaCl}_{2}, 0,6 \% \mathrm{NaCl}, 1 \%$ kitin, dilarutkan dalam $1 \mathrm{~L}$ air laut steril sampai $\mathrm{pH}$ 7,0. Kemudian diautoclave pada temperatur $121^{\circ} \mathrm{C}$, $1 \mathrm{~atm}$, selama 15 menit. Sedangkan mineral salt agar plate $0,4 \%\left(\mathrm{NH}_{4}\right)_{2} \mathrm{SO}_{4}$, $0,1 \% \mathrm{~K}_{2} \mathrm{HPO}_{4}, 0,01 \% \mathrm{MgSO}_{4} .7 \mathrm{H}_{2} \mathrm{O}, 0,01$ $\% \mathrm{CaCl}_{2}, 0,6 \% \mathrm{NaCl}, 1 \%$ kitin, dilarutkan 
dalam $1 \mathrm{~L}$ air laut steril sampai $\mathrm{pH} 7,0$. Kemudian diautoclave pada temperatur $121^{\circ} \mathrm{C}$, 1 atm, selama 15 menit (M.Al-tai, et al., 1989).

\section{Seleksi Actinomycetes}

Isolasi Actinomycetes yang diperoleh dari tahap isolasi, diuji kemampuannya dalam mendegradasi kitin. Isolat Actinomycetes yang tumbuh pada media ISP-2 diinokulasi pada mineral salt agar plate. Kemudian diinkubasi selama 5 hari. Pada akhir inkubasi, mineral salt agar plate dipenuhi dengan larutan Congo Red $1 \%$ selama 15 menit. Lalu dibilas dengan $1 \mathrm{M}$ $\mathrm{NaCl}$ selama 15 menit. Adanya zona bening yang terbentuk mengidentifikasikan terjadinya degradasi kitin. Semakin besar zona bening yang terbentuk mengidentifikasikan bahwa semakin besar pula kemampuan Actinomycetes tersebut dalam menghasilkan enzim kitinase.

\section{HASIL DAN PEMBAHASAN}

Actinomycetes merupakan organisme tanah yang memiliki sifat-sifat yang umum dimiliki oleh bakteri dan jamur. Terlihat dari luar seperti jamur (eukariotik), namun organisme ini sesuai dengan semua kriteria untuk sel prokariotik, yaitu : dinding selnya mengandung asam muramat, tidak mempunyai mitokondrion, mengandung ribosom 70s, tidak mempunyai pembungkus nukleus, garis tengah selnya berkisar dari 0,5-2,0 $\mu \mathrm{m}$, dan dapat dimatikan atau dihambat oleh banyak antibiotik bakteri (Wesley dan Wheeler, 1993 dan Rao, 1994).

Menurut Alexander, 1997, Actinomycetes memiliki dinding sel yang terdiri dari polimer-polimer gula, asam amino dan asam gula seperti dinding sel bakteri Gram positif. Sedangkan dinding sel fungi terdiri dari selulosa dan kitin. Hal tersebut sejalan dengan Lay dan Hastowo (1992), yang mengatakan bahwa Actinomycetes merupakan kelompok mikroba bersifat Gram positif. Strain actinomycetes ini ditumbuhkan dalam media ISP-2. Isolate actinomycetes yang digunakan adalah ANL--12, ANL-9, ANLd-2b-3, dan ANL-4. Isolat ANL-4 yang diperoleh memiliki kemiripan dengan gambar mikroskopis dari streptomyces $s p$ yang telah berhasil diisolasi dari tanah oleh Nikolova, et al. pada 2006-2007, sehingga dapat dikatakan bahwa isolat ANL-4 termasuk ke dalam genus streptomyces. Sterptomycetes, terdiri dari 4 genus dengan ciri-ciri diameter filamen $0,5-2,0 \mu \mathrm{m}$, rantai 
terdiri dari tiga hingga beberapa spora, miselium aerial, dan dapat memproduksi antibiotik. Contoh : Strepomyces (Gambar $1)$.

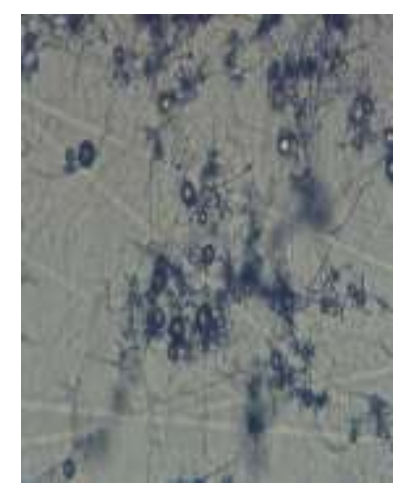

ANL-12

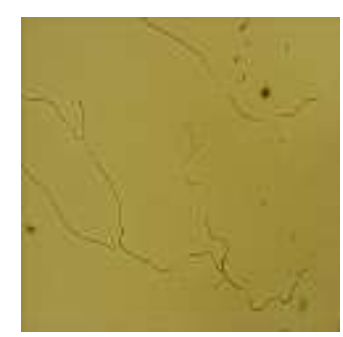

ANL-4

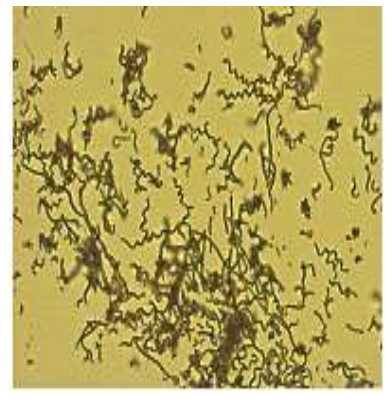

ANLd-2b-3

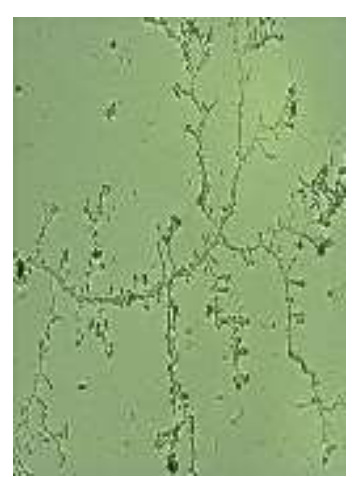

ANL-9

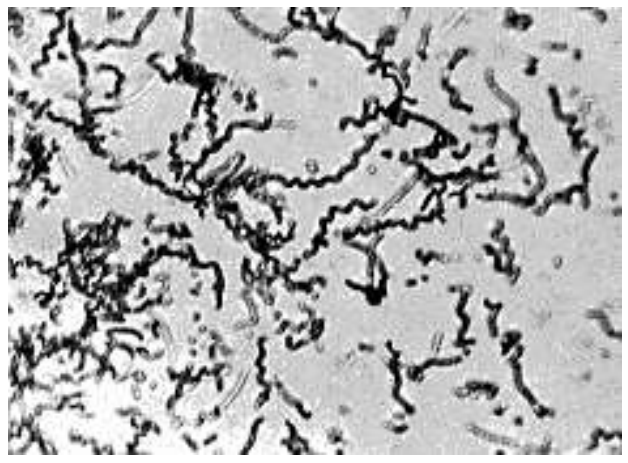

Nikolova, et al. pada 2006-2007

Gambar 1. Isolat actinomycetes secara mikroskopik

Masing-masing isolate tersebut memiliki indeks kitinolitik yaitu 1,9 cm, 2,0 cm, 2,3 $\mathrm{cm}$, dan 5,0 cm (Gambar 2). Berdasarkan hasil tersebut bahwa isolate ANL-4 yang memiliki indeks kitinolitik tertinggi dibandingkan isolate yang lain, hal ini ditentukan berdasarkan rasio diameter zona bening yang dihasilkan terhadap diameter koloni, yang artinya bahwa semakin tinggi nilai indeks kitinolitik maka semakin besar isolate tersebut memiliki kemampuan enzim mendegradasi subtrat (Tabel 1 dan Gambar 2).

Tabel 1. Indeks kitinolitik actinomycetes yang diisolasi dari Lumpur Hutan Bakau asal Pantai Ringgung Perairan Teluk Lampung 


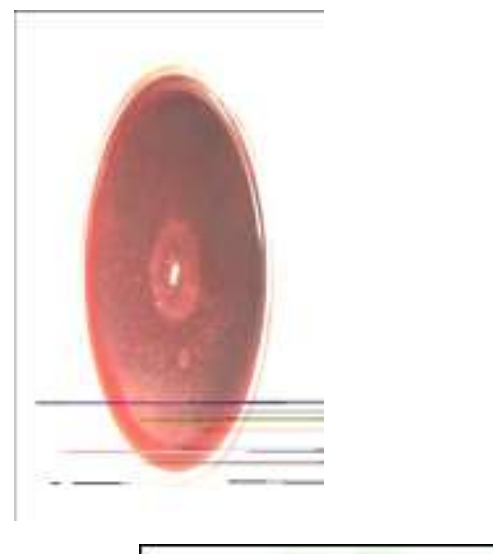

ANL-12

ANL-9

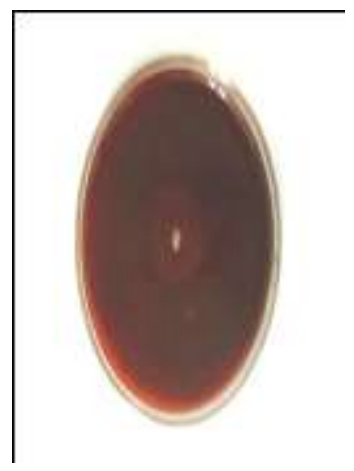

ANL-4

Gambar 2. Actinomycetes yang mempunyai kemampuan dalam mendegradasi kitin pada media mineral- salt agar plate dengan Kitin 1\% dengan

\begin{tabular}{llll}
\hline Kode Isolat & $\begin{array}{l}\text { Diameter } \\
\text { Zona } \\
\text { Bening }(\mathrm{cm})\end{array}$ & $\begin{array}{l}\text { Diameter } \\
\text { Koloni }(\mathrm{cm})\end{array}$ & $\begin{array}{l}\text { Indeks } \\
\text { Kitinoli } \\
\text { tik }\end{array}$ \\
\hline ANL -12 & 2,3 & 1,2 & 1,9 \\
\hline ANL -9 & 1,0 & 0,5 & 2,0 \\
\hline ANLd $-2 \mathrm{~b}$ & 0,7 & 0,3 & 2,3 \\
-3 & & & \\
\hline ANL -4 & 0,5 & 0,1 & 5,0 \\
& \multicolumn{2}{l}{ pewarnaan Congo Red $1 \%$} &
\end{tabular}

pewarnaan Congo Red $1 \%$

\section{SIMPULAN DAN SARAN}

Isolasi Actinomycetes dari lumpur hutan bakau dengan menggunakan media NaST21Cx berhasil dilakukan dengan diperoleh empat isolat Actinomycetes yang diberi kode ANL-4, ANL-9, ANL-12, dan ANLd-2b-3 yang diidentifikasi dengan mengamati hifa dan spora yang terbentuk menggunakan mikroskop dengan perbesaran 400 x. Isolat ANL-4, ANL-9, ANL-12, dan ANLd-2b-3 memiliki aktivitas kitinolitik pada media mineralsalt agar dengan kitin 1\% (w/v) dengan indeks kitinolitik berturut-turut $5 \mathrm{~cm}, 2 \mathrm{~cm}$, $1,9 \mathrm{~cm}$, dan $2,3 \mathrm{~cm}$

Untuk penelitian selanjutnya disarankan menggunakan variasi media dalam 
melakukan isolasi Actinomycetes agar Actinomycetes yang diperoleh lebih beragam, melakukan identifikasi secara biologi molekuler untuk mengetahui spesies dari Actinomycetes hasil isolasi, menentukan waktu optimum sebelum pemanenan enzim kitinase dari isolat ANL-4, ANL-9, ANL-12 dan ANLd-2b-3 agar aktivitas dari enzim yang dihasilkan juga besar, menggunakan variasi zat pewarna dalam melakukan seleksi Actinomycetes agar zona bening Actinomycetes yang diperoleh lebih besar dan terlihat.

\section{DAFTAR PUSTAKA}

Alexander, M.1997. Introduction of soil Microbiology, Second Edition. John willey and Sons. Inc. New York.

Anonim. 1999. Biologi Molekuler. http:///id.

Wikipedia.org/wiki/Sekuensing_ vcasam nukleat. Update : 15 Juni 2009.11.00

Cohen-Kupiec R, Chet I. 1998. The molecular biology of chitin digestion. Curr Opinion Biotechnol 9: 270-277. Departemen Kelautan dan Perikanan Republik Indonesia. 2003. Perkembangan ekspor komoditi hasil perikanan Indonesia 1998-2002.url: http://www.dkp. go.id/. Update 10 Juni 2009. 10.15

Dodane V, Vilivalam VD. 1998. Pharmaceutical applications of chitosan. PSTT 1:246 253

Fithria, N. 2007. Uji Antibakteri Isolat Actinomycetes dari Callispongia sp. yang Terdapat Di Pulau Tegal dan Pulau Tangkil Perairan Teluk Lampung. Skripsi. FMIPA. Unviversitas Lampung. Bandar Lampung

Fukamizo T. 2000. Chitinolityc enzymes: catalysis, substrate binding, and their application. Curr Prot Peptide Sci 1: 105-124.

Gijzen M, Kuflu K, Qutob D, Chernys JT. 2001. A class I chitinase from soybean seed coat. J Exp Bot 52: 2283-2289.

Gooday GW. 1994. Physiology of microbial degradation of chitin and chitosan. In Ratledge C, editor. Biochemistry of Microbial Degradation. Netherlands: Kluwer Academic Publ. p: 279-312.

Hirano S. 1996. Chitin biotechnology applications. Biotechnol Annu Rev, 2:237-258

Lay, B.W dan S. Hastowo,. 1992. 
Mikrobiologi. Rajawali Press. Jakarta

Lehninger, 1982. Dasar-dasar Biokimia.

Erlangga. Jakarta

Linden, J., Stoner, R., et al., 2007.

"Organic Disease Control Elicitors".

Agro Food Industry. New York

Martín-Gil FJ, Leal JA, Gómez-Miranda B,

Martín-Gil J, Prieto A, Ramos

Sánchez MC. "Low temperature

thermal behaviour of chitins and chitin-glucans". Thermochim. Acta, 1992, vol. 211, pp. 241-254

Nikolova, Stefka Antonova, Vanya

Stefanova, dan Lyubomira Yocheva. 2006-2007. Taxonomic Study of Streptomyces $\quad s p$. Strain 34-1. Journal of Culture Collections, Volume 5 pp. 10-15.

Ohno T, Armand S, Hata T, Nikaidou N, Henrissat B, Mitsutomi M, Watanabe T. 1996.A modular family 19 chitinase found in the prokaryotic organism Streptomyces griceus HUT 6037. J Bacteriol 178: 5065-5070

Old, R.W., dan Primrose S.B.1989. Prinsip-prinsip Manipulasi Gen. Edisi Keempat. Publisher Business Service USA. Hal. 4-7, 182-184.

Patil, R. S., V. Chormade, and M. V.
Desphande. 2000. Chitinolytic enzymes an exploration. Enz Microb Technol 26:473-483.

Pemerintah Daerah Lampung dan Proyek Pesisir Lampung. Atlas. Sumberdaya Wilayah Pesisir Lampung. Diakses tanggal 18 april 2008.

Poedjiadi, Anna. 1994. Dasar-dasar

Biokimia. UI-Press. Jakarta

Rao, N.S.S.1994. Mikroorganisme Tanah dan Pertumbuhan Tanaman. UIPress. Jakarta.

Singh, J., N. Batra and R.C. Sobti, 1999. Purification and characterization of alkaline cellulose produced by a novel isolate, Bacillus sphaericus JS1.J. Ind. Microbiol. Biotechnol., 31: $51-59$

Skjak-Braek GA, Athonsen T, Sandford PT. 1989. Chitin and Chitosan: Sources, Chemistry, Biochemistry, Physical Properties and Applications. Elsevier Appl Sci, London. p:561.

Suhartono M.T. 1989. Enzim dan Bioteknologi. Pusat Antar Universitas Bioteknologi, IPB

Tiffany A. Reese, Hong-Erh Liang, Andrew M. Tager, Andrew D. Luster, Nico Van Rooijen, David Voehringer \& Richard M. Locksley (3 May 2007). "Chitin induces 
accumulation in tissue of innate immune cells associated with allergy". Nature 447: 92-96.

Tomlinson, P,B.1999. TheBotany of Mangroves. Cambridge University Press.USA : 3

Tsigos, I., A. Martinou, Kafetzopoulos and V. Bouriotis. 2000. Chitin deacetylases: New versatile tools in biotechnology. TIBTECH Rev, 18: 305-312.

Tsigos I. dan V. Bouriotis. 1995. Purification and characterization of chitin deacetylase from Colletotrichum lindemuthianum . J Biol Chem, 270:26286 26291

Volk, W.A dan M.F.Wheeler.1993. Mikrobiologi Dasar, Penerjemah Markham Edisi Kelima. Erlangga. Jakarta. 